\title{
ALTERAÇÃO DA MICRODUREZA SUPERFICIAL DO ESMALTE DENTÁRIO EXPOSTOS A CHÁS INDUSTRIALIZADOS
}

\author{
Nayanna Lana Soares Fernandes* \\ Ingrid Andrade Meira* \\ Juliane Rolim de Lavôr ${ }^{\star \star \star x}$ \\ Andressa Feitosa Bezerra de Oliveira ${ }^{* *+x}$ \\ Fábio Correia Sampaio ${ }^{* * *+*}$
}

\begin{abstract}
RESUM0: 0 presente estudo avaliou o potencial erosivo de chás industrializados no esmalte dentário, de acordo com 0 percentual de perda de dureza superficial (\%PMD), pH, titulação ácida e capacidade tampão. Foram analisados seis tipos de chás industrializados, de diferentes marcas e sabores. A água mineral-Crystal ${ }^{\circledR} \mathrm{e}$ a Coca-Cola ${ }^{\circledR}$ foram os controles negativo e positivo, respectivamente. As medições de pH e titulação ácida foram feitas em triplicata, em $50 \mathrm{~mL}$ da bebida. A capacidade tampão foi calculada baseada nos valores de pH e titulação ácida para $0 \mathrm{pH} \mathrm{7,0.} \mathrm{A} \mathrm{microdureza} \mathrm{da} \mathrm{superfície} 0$ esmalte foi medida antes e após 0 teste erosivo. Os testes Anova e a correlação de Pearson, com $p<0,05$, foram usados para analisar os dados. Os dados apresentaram uma distribuição normal. Foi verificada diferença significativa entre os chás e os controles utilizados, em todas as variáveis analisadas (ANOVA, $p<0,05$ ). 0 pH dos chás variou de 2,25 (chá preto com limão) a 3,39 (chá mate com limão). Os maiores valores de titulação ácida $(2,05)$ e capacidade tampão $(8,30)$ foram apresentados pelo chá preto com limão. 0 maior \%PMD foi encontrado no chá de pêssego e 0 menor no chá natural do mate. Foram verificadas diferenças estatisticamente significante no \%PMD de todos os chás com o controle negativo. $0 \%$ PMD de todos os chás foi superior ao controle positivo. Correlações significativas $(p<0,05)$ foram observadas entre pH inicial com titulação ácida e capacidade tampão, e \%PMD com pH inicial, titulação ácida e capacidade tampão. Assim, todos os chás analisados apresentaram caráter erosivo no esmalte dentário, variando a sua intensidade conforme o sabor e/ou composição dos mesmos.
\end{abstract}

PALAVRAS-CHAVE: Erosão dentária; Bebidas; Esmalte dentário.

\section{ALTERATIONS IN SURFACE MICRO-HARDNESS OF DENTAL ENAMEL EXPOSED TO INDUSTRIALIZED TEAS}

\begin{abstract}
The erosion capacity of industrialized teas on the dental enamel is evaluated according to the percentage of dental surface hardness loss (\%DHL), pH, acid titration and buffer capacity. Six types of industrialized teas, featuring different brands and tastes, were analyzed. Mineral water-Crystal ${ }^{\circledR}$ and Coca-Cola ${ }^{\circledR}$ were respectively the negative and positive controls. Measurements of $\mathrm{pH}$ and titration were prepared in triplicate, in a $50 \mathrm{ml}$ beverage. Buffer capacity was calculated on $\mathrm{pH}$ rates and acid titration for $\mathrm{pH}$ 7.0. Micro-hardness of enamel surface was evaluated prior to and after the erosive test. ANOVA and Pearson's correlation tests at $p<0.05$ were employed to analyze data which, in turn, provided normal distribution. There was significant difference between the teas and controls in all variables (ANOVA, $p<0.05$ ). The $\mathrm{pH}$ of teas ranged between 2.25 (Black tea with lemon) and 3.39 (Matte with lemon). Highest rates for acid titration (2.05) and buffer capacity (8.30) occurred in Black tea with lemon. Highest \%DHL rate occurred in Peach tea, whilst the lowest in Natural Matte tea. There was a statistically significant difference in \%DHL for all teas when compared to negative control and \%PMD of all types of tea was higher than that of positive control. There were significant co-relationships $(p<0.05)$ between initial pH initial with acid titration and buffer capacity, and between \%PMD and initial pH, acid titration and buffer capacity. Results showed that all teas had an erosive trait on the dental enamel, with intensity variation according to taste and composition.
\end{abstract}

KEYWORDS: Dental erosion; Beverages; Dental enamel.

\footnotetext{
Discente da graduação de Odontologia, Universidade Federal da Paraíba (UFPB), Brasil. E-mail: naaah.soares.fernandes@hotmail.com

** Mestranda em Clínica Odontológica - Prótese Dentária pela Universidade Estadual de Campinas (FOP/UNICAMP), Brasil.

*** Discente da graduação de Odontologia, Universidade Federal da Paraíba (UFPB), João Pessoa (PB) Brasil.

${ }^{* * *}$ Doutora em Odontologia (Odontopediatria) pela Universidade de Pernambuco Docente do Departamento de Morfologia, Universidade Federal da Paraíba (UFPB), João Pessoa (PB) Brasil.

${ }^{* * * * *}$ Doutor em Cariologia. Universidade de 0slo, UIO, Noruega. Docente do Departamento de Odontologia Clínica e Social, Universidade Federal da Paraíba (UFPB), João Pessoa (PB), Brasil.
} 


\section{INTRODUÇÃO}

A erosão dental é definida como a perda de tecido dentário mineralizado por meio da dissolução ácida (LUSSI et al., 2011; WEST; JOINER, 2014). Esta patologia é um problema crescente e, frequentemente, está ligada aos hábitos alimentares e estilo de vida dos indivíduos, podendo estar associada ao consumo de alimentos ácidos e refrigerantes (KREULEN et al., 2010; LUSSI et al., 2014). A erosão diferentemente da cárie dentária não necessita da presença das bactérias do biofilme, ocorrendo, portanto, sem 0 envolvimento de microrganismos (LUSSI et al., 2000; REDDY et al., 2016)

Clinicamente, as lesões apresentam uma superfície lisa, opaca e transparente, com a borda em esmalte intacto na margem gengival. Há presença de depressões e concavidades nas superfícies, acarretando a perda da morfologia dental (CARVALHO et al., 2014). Em casos mais graves, pode haver exposição da dentina e/ou do tecido pulpar (MESSIAS et al., 2011). Além disso, a mesma pode também apresentar uma aparência clínica com envolvimento de um componente de fricção, tais como abrasão ou desgaste, principalmente em indivíduos com idades avançadas (MULLER-BOLLA et al., 2015). É importante ressaltar que o diagnóstico seja feito precocemente, pois a prevenção é a forma mais eficaz de evitar essa patologia (GONÇALVES et al., 2012). No entanto, a natureza multifatorial da erosão dentária (LUSSI et al., 2012; JAEGGI; LUSSI, 2014) dificulta, muitas vezes, a realização de um diagnóstico precoce e correto (LUSSI; GANSS, 2014).

Atualmente, a erosão dentária é um problema mundial (CARVALHO et al., 2014). Durante muito tempo, os refrigerantes foram extensivamente investigados e representam, sem dúvida, um dos principais fatores etiológicos extrínsecos desta patologia (SINGH; JINDAL, 2010; SHELLIS; ADDY, 2014). Os sucos de frutas, bebidas carbonadas e chás são as bebidas consumidas com frequência (SINGH; JINDAL, 2010).

Há, no mercado brasileiro, grande diversidade de ofertas de bebidas industrializadas, prontas para consumo, o que tem estimulado e diversificado a ingestão das mesmas. Os chás estão entre as bebidas industrializadascomercialmentedisponíveisnomercado brasileiro, e o seu grande consumo está associado aos benefícios trazidos para a saúde, pois é uma bebida que demonstra ter propriedades antioxidantes. Assim, observa-se aumento na prevalência dos casos de erosão dentária, além de mudanças significativas nos costumes comportamentais e alimentares da população, causando maior preocupação e alerta para a comunidade científica sobre a relevância do tema (GONÇALVES et al., 2012).

Diversos estudos mundiais relatam significativo aumento nos índices de prevalência da erosão dentária, especialmente em crianças e adultos jovens (JAEGGI; LUSSI, 2014). De acordo com Alvarez et al. (2015), a prevalência da erosão dentária em crianças de 12 anos, pode variar de $13 \%$ a $75 \%$, visto que os dentes decíduos apresentam uma camada mais fina de esmalte, aumentando o risco e a progressão desta patologia. As crianças e adolescentes são considerados uma população de risco, quando se trata de erosão dentária, devido, especialmente, ao seu comportamento alimentar, principalmente pelo aumento no consumo de agentes ácidos por esse público, nos últimos anos (GONÇALVES et al., 2012).

Portanto, diante do consumo desenfreado de bebidas ácidas, na atualidade, e diante da grande preocupação com 0 crescimento da prevalência de erosão em todo o mundo, este estudo teve como objetivo avaliar o potencial erosivo de chás industrializados, no esmalte dentário humano. Para isso, foram coletados os dados de pH, titulação ácida para o pH 7.0 e a capacidade tampão, das bebidas, e avaliados o percentual de perda de dureza superficial (\%PMD) do esmalte.

\section{METODOLOGIA}

Este estudo foi do tipo laboratorial, in vitro, duplo-cego, com seleção aleatória, aprovado pelo 
Comitê de Ética em Pesquisa, do Centro de Ciências da Saúde, daUniversidade Federal daParaíbapelo protocolo n. 0285/13 (CAAE: 17581413.4.0000.5188). Todos os doadores assinaram 0 Termo de Consentimento Livre e Esclarecido, conforme resolução 466/12 da CNS.

\subsection{SELEÇÃO DAS BEBIDAS}

Os tipos de chás, composição, marca, fabricante dos produtos utilizados, estão apresentados no Quadro 1. Para os controles negativo e positivo foram utilizados a água mineral Crystal (Coca-Cola Brasi $^{\circledR}$ ) e a Coca-Cola ${ }^{\circledR}$, respectivamente. As bebidas industrializadas, prontas para 0 consumo, foram armazenadas conforme as instruções do fabricante.

\subsection{PREPARAÇÃO DOS ESPÉCIMES}

Foram utilizados 30 dentes humanos, extraídos por razões ortodônticas ou impactação, armazenados em formol a $10 \%$, em temperatura ambiente, até 0 seu uso. Os dentes foram examinados com 0 auxílio de uma lupa de $5 x$ de aumento para averiguação de possíveis trincas, rachaduras, cáries e alterações do esmalte, situação que foram excluídos da amostra.

Foi preparado um total de 64 blocos de esmalte $(4 \times 4 \times 2 \mathrm{~mm})$, das superfícies vestibular e lingual dos dentes, utilizando-se um disco diamantado dupla face, em cortadeira de precisão (Labcut 1010), sob irrigação constante. Os espécimes foram embebidos em resina acrílica para planificação em politriz metalográfica (PSK-2V, Skill-tec Comércio e Manutenção Ltda, São Paulo, SP, Brazil), utilizando-se lixas de silicone de granulações variadas $(600-1500)$, sob irrigação constante. 0 polimento da superfície do esmalte foi realizada com feltros umedecidos e suspensão de

Quadro 1. Informações sobre o sabor, composição e marca/fabricante das bebidas analisadas

\begin{tabular}{|c|c|c|}
\hline Tipo de bebida & Composição & Marca/Fabricante \\
\hline Chá preto com limão & $\begin{array}{l}\text { Água, açúcar, suco concentrado de limão, extrato aquoso de chá preto (Camellia } \\
\text { sinensis), aroma sintético idêntico ao natural, acidulantes ácido cítrico e ácido fosfórico, } \\
\text { regulador de acidez citrato de sódio e antiespumante dimetilpolisiloxano. }\end{array}$ & Leão Fuze $®$ \\
\hline Chá matte com limão & $\begin{array}{l}\text { Água, açúcar, extrato aquoso de mate (llex paraguariensis St. Hil.), suco concentrado de } \\
\text { limão, aroma sintético idêntico ao natural, antioxidante ácido ascórbico, conservadores } \\
\text { sorbato de potássio e benzoato de sódio. }\end{array}$ & Matte Leão® \\
\hline Chá branco & $\begin{array}{l}\text { Água, chá branco em pó (Carmellia sinensis), vitamina C, acidulantes ácido cítrico e } \\
\text { ácido málico, reguladores de acidez citrato de sódio, edulcorantes ciclamato de sódio } \\
\text { ( } 40 \mathrm{mg} / 100 \mathrm{ml}) \text {, sucralose }(6 \mathrm{mg} / 100 \mathrm{ml}) \text { e sacarina sódica }(4 \mathrm{mg} / 100 \mathrm{ml}) \text {. }\end{array}$ & Feel Good@ \\
\hline Chá verde & $\begin{array}{l}\text { Água, chá verde em pó (Carmellia sinensis), vitamina C, reguladores de acidez citrato } \\
\text { de sódio e citrato de pótassio, acidulantes ácido cítrico e ácido málico, aroma idêntico } \\
\text { ao natural de imão e edulcorantes ciclamato de sódio ( } 40 \mathrm{mg} / 100 \mathrm{ml}) \text { e sacarina sódica } \\
(4 \mathrm{mg} / 100 \mathrm{ml}) \text {. }\end{array}$ & Feel Good $®$ \\
\hline Chá de pessêgo & $\begin{array}{l}\text { Água, suco concentrado de pêssego, extrato aquoso de chá preto (Carmellia sinensis), } \\
\text { acidulante ácido cítrico e ácido fosfórico, aroma sintético idêntico ao natural, regulador } \\
\text { de acidez citrato de sódio, edulcorantes sucralose ( } 12 \mathrm{mg} \text { ) e acesulfame de potássio (5 } \\
\text { mg) por } 100 \mathrm{ml} \text {, antiespumane dimetilpolisiloxano. }\end{array}$ & Leão Fuze $®$ \\
\hline Chá natural do matte & $\begin{array}{l}\text { Açúcar, água, extrato de chá mate, aromatizante aroma idêntico ao natural, acidulante } \\
\text { ácido cítrico (INS 330) e antioxidante ácido ascórbico (INS 330). Não contém glúten. }\end{array}$ & Maguary® \\
\hline $\begin{array}{l}\text { Refrigerante a base de cola } \\
(\text { Coca-Cola } \AA)\end{array}$ & $\begin{array}{l}\text { Bicarbonato }(62,49 \mathrm{mg} / \mathrm{L}) \text {, cálcio }(7,792 \mathrm{mg} / \mathrm{L}) \text {, carbonato }(3,91 \mathrm{mg} / \mathrm{L}) \text {, cloreto } \\
(0,09 \mathrm{mg} / \mathrm{L}) \text {, Estrôncio }(0,342 \mathrm{mg} / \mathrm{L}) \text {, fluoreto }(0,05 \mathrm{mg} / \mathrm{L}), \mathrm{magnésio}(0,340 \mathrm{mg} / \mathrm{L}) \text {, } \\
\text { potássio }(1,485 \mathrm{mg} / \mathrm{L}) \text {, sódio }(16,090 \mathrm{mg} / \mathrm{L}) \text {, Sulfato }(0,18 \mathrm{mg} / \mathrm{L}) \text {. }\end{array}$ & $\begin{array}{l}\text { Coca-Cola } \AA / \\
\text { The Coca-Cola } \\
\text { Company® }\end{array}$ \\
\hline Água mineral & $\begin{array}{l}\text { Cloreto=23,80; sódio=14,99; nitrato=2,9; bicarbonato }=0,80 ; \text { sulfato }=0,8 ; \\
\text { potássio }=0,79 ; \text { magnésio=0,76; cálcio }=0,23 ; \text { bário }=0,027 \text { e estrôncio }=0,006 \text {. }\end{array}$ & $\begin{array}{l}\text { Coca-Cola Brasil@/ } \\
\text { Fountain Água } \\
\text { Mineral Ltda® }\end{array}$ \\
\hline
\end{tabular}


diamante de $1 \mu \mathrm{m}$. Os blocos foram então limpos por 5 minutos de sonicação, em água destilada, utilizando um dispositivo ultrassônico. Em seguida, as amostras foram divididas, aleatoriamente, entre os grupos, de acordo com os valores de dureza superficial inicial.

Antes do teste erosivo, a superfície do esmalte, de cada espécime, foi dividida em três partes iguais, sendo que as extremidades foram recobertas com duas camadas de esmalte de unhas (Risque, Niassi, Taboão da Serra, São Paulo, Brasil) e a parte central (1 $\mathrm{mm}$ ) permaneceu descoberta, onde foi produzida a erosão. Assim, cada amostra serviu como uma unidade experimental independente.

Asamostrasforam distribuídas, aleatoriamente, em oito grupos experimentais $(n=8)$ : (1) chá preto com limão, (2) chá mate com limão, (3) chá branco, (4) chá verde, (5) chá de pêssego, (6) chá natural do mate, (7) água mineral, (8) refrigerante Coca-Cola ${ }^{\circledR}$.

\subsection{COLETA DE DADOS}

As bebidas, imediatamente após a sua abertura, tiveram os seus $\mathrm{pH}$ mensurados, utilizandose um eletrodo acoplado a um medidor de pH (Orion, modelo 420A - Thermo Fischer Science Inc., Waltham, MA), devidamente calibrado.

A titulação ácida foi realizada com a adição da solução padrão de $1 \mathrm{M} \mathrm{NaOH}$ a $50 \mathrm{~mL}$ de cada bebida, em incrementos de $0,2 \mathrm{~mL}$, utilizando um agitador magnético, até atingir o pH 7,0. A capacidade tampão () foi calculada de acordo com Lussi et al. (2012): $=\mathrm{C} / \mathrm{pH}$, em que $C$ é a quantidade total de base utilizada para aumentar 0 pH inicial até 0 pH 7.0 e pH é a variação do a pH da solução. Para garantir maior precisão, as medições foram realizadas em triplicata, para cada bebida e a média aritmética calculada.

Para 0 teste erosivo, as amostras foram imersas em $50 \mathrm{~mL}$ ( $6 \mathrm{~mL} /$ espécime) da bebida, em temperatura ambiente, durante 02 horas, sem agitação. Todas as bolhas na superfície da amostra foram removidas por suave agitação. Ao término deste tempo, as amostras foram removidas e lavadas com água deionizada e armazenadas em ambiente úmido, para prevenir o ressecamento, até a sua avaliação.
A determinação da dureza superficial foi realizada por meio de um microdurômetro (Shimadzu HMV - AD Easy Test Version 3.0.00), com um penetrador diamantado do tipo Vickers, sob uma pressão de $50 \mathrm{~g}$ por 15 segundos. A microdureza foi calculada pela dimensão da indentação com software específico. Foram executadas seis endentações para cada amostra, a uma distância de 70m cada, destas, três foram realizadas no esmalte hígido (antes do teste erosivo) e as outras três na amostra erodida (após 0 teste erosivo). Foi calculada a média aritmética das amostras, referente ao esmalte hígido e erodido. Posteriormente, foi realizado 0 cálculo do percentual da perda de dureza superficial (\%PMD), de acordo com a seguinte fórmula: $P M D=M D i-M D f / M D i x 100$ ( $M d i=$ Média da Microdureza inicial do esmalte e MDf = Média da Microdureza final do esmalte).

\subsection{ANÁLISE ESTATÍSTICA}

Os dados de pH, titulação ácida, capacidade tampão e \%PMD apresentaram distribuição normal pelo teste Shapiro-Wilk, permitindo a utilização de testes paramétricos. Para comparar os dados de $\% \mathrm{PMD}$, entre as bebidas avaliadas, utilizou-se 0 teste Anova, seguido do teste de Tukey. As correlações entre as variáveis foram feitas com 0 teste de Pearson. 0 nível de significância considerado foi de $95 \%$ ( $p<$ $0,05)$.

\section{RESULTADOS}

$0 \mathrm{pH}$ das bebidas variou de 2,25 a 10,10. Dentre os chás avaliados, os menores valores para titulação ácida e a capacidade tampão foram

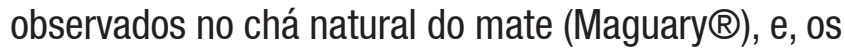
maiores, no chá preto com limão (Leão Fuze $®)$ ). Todos os valores de titulação ácida e capacidade tampão foram superiores ao do controle negativo e inferiores ao do controle positivo, com exceção da titulação ácida apresentada pelo chá preto com limão (Leão Fuze®), conforme observado na Tabela 1. 
Tabela 1. Valores médios ( $\pm \mathrm{Dp})$ de pH, titulação ácida (mmol ; $1 \mathrm{NaOH}$ para o pH 7.0) e capacidade tampão C/pH) de todas as bebidas analisadas

\begin{tabular}{|c|c|c|c|}
\hline Tipo de bebida & pH inicial (dP) & Titulação ácida (dP) & Capacidade tampão (dP) \\
\hline \multicolumn{4}{|l|}{ Chás industrializados } \\
\hline Chá preto com limão & $2,25(0,76)^{c}$ & $2,05(0,08)^{b, c}$ & $8,29(0,44)^{b, c}$ \\
\hline Chá mate com limão & $3,39(0,02)^{c}$ & $0,76(0,02)^{c}$ & $4,17(0,17)^{c}$ \\
\hline Chá branco & $3,07(0,00$ & $1,21(0,07)^{c}$ & $6,04(0,36)^{c}$ \\
\hline Chá verde & $3,38(0,00)^{c}$ & $0,88(0,02)^{c}$ & $4,81(0,13)^{c}$ \\
\hline Chá de pêssego & $2,51(0,02)^{b, c}$ & $1,3(0,19)^{c}$ & $5,86(0,64)^{c}$ \\
\hline Chá natural do mate & $3,30(0,03)^{c}$ & $0,57(0,02)^{c}$ & $3,07(0,15)^{c}$ \\
\hline \multicolumn{4}{|l|}{ Controle positivo } \\
\hline Coca-cola & $2,47(0,01)^{b}$ & $1,96(0,20)^{b}$ & $8,35(0,86)^{b}$ \\
\hline \multicolumn{4}{|l|}{ Controle negativo } \\
\hline Água mineral & $8,59(0,08)^{\mathrm{a}}$ & $0(0,00)^{\mathrm{a}}$ & $0(0,00)^{\mathrm{a}}$ \\
\hline
\end{tabular}

Em relação ao \%PMD dos chás, nota-se que as maiores perdas de dureza foram provenientes dos chás de pêssego (Leão Fuze®) e branco (FeelGood®), enquanto que a menor foi encontrada no chá natural do mate (Maguary $囚)$, conforme dados presentes na Tabela 2. Todos os chás tiveram \%PMD maior do que os controles. Foi verificada diferença significativa entre todos os chás e a água mineral (controle negativo). 0 controle positivo não apresentou diferenças significativas com os chás verde (FeelGood@) e natural do mate (Maguary®).
Foram

observadas

correlações estatisticamente significantes entre as variáveis: $\mathrm{pH}$ e titulação ácida ( $r=-0,771, p<0,01)$; $\mathrm{pH}$ e capacidade $(r=-0,838, p<0,01)$; titulação ácida e capacidade tampão ( $r=0,984, p<0,01) .0 \%$ PMD também foi sifnificativo com todas as variáveis químicas: $\mathrm{pH}(\mathrm{r}=-$ $0,861, p<0,01)$, titulação ácida $(r=0,557, p<0,01)$ e capacidade tampão $(r=-0,639, p<0,01)$.

Tabela 2. Valores de \%PMD dos chás avaliados comparados aos controles

\begin{tabular}{lccccc}
\hline & & \multicolumn{2}{c}{ Controle negativo Água mineral® } & \multicolumn{2}{c}{ Controle positivo Coca-cola® } \\
\hline & \%PMD(dP) & \%PMD(dP) & $\boldsymbol{P}^{\star}$ & \%PMD(dP) & $\boldsymbol{P}^{\star}$ \\
\cline { 2 - 5 } Chá preto com limão & $54,47(6,11)$ & $-0,03(3,7)$ & 0,00 & $30,46(7,36)$ & 0,00 \\
Chá mate com limão & $49,39(9,90)$ & $-0,03(3,7)$ & 0,00 & $30,46(7,36)$ & 0,00 \\
Chá branco & $57,10(11,60)$ & $-0,03(3,7)$ & 0,00 & $30,46(7,36)$ & 0,00 \\
Chá verde & $41,71(12,03)$ & $-0,03(3,7)$ & 0,00 & $30,46(7,36)$ & 0,00 \\
Chá de pêssego & $57,69(9,01)$ & $-0,03(3,7)$ & 0,00 & $30,46(7,36)$ & 0,00 \\
Chá natural do mate & $38,38(8,50)$ & $-0,03(3,7)$ & 0,00 & $30,46(7,36)$ & 0,00 \\
\hline
\end{tabular}

*Anova seguido do teste de Tukey, significativo quando $p<0,05$ 


\section{DISCUSSÃO}

A erosão dentária tem sido considerada um problema crescente de saúde bucal (KREULEN et al., 2010; JAÂFOURA et al., 2012). 0 alto consumo de bebidas e alimentos ácidos representam fatores extrínsecos relevantes para 0 desenvolvimento desta patologia dentária (LUSSI et al., 2012; LUNKES; HASHIZUME, 2014). A modificação no estilo de vida tem contribuído para 0 aumento da quantidade e da frequência de consumo de produtos ácidos (LUSSI et al., 2012). 0 chá, bebida bastante consumida em todo o mundo (JAÂFOURA et al., 2012), é incorporado à dieta alimentar de muitas pessoas, como substituto saudável a outras bebidas industrializadas, consideradas prejudiciais (LUNKES; HASHIZUME 2014). No mundo, os três principais tipos de chás consumidos são: verde, preto e oolong (JAÂFOURA et al., 2012). No presente estudo, foram avaliados os chás verde, preto, branco e mate, dentre os quais, três eram frutados, selecionados de acordo com o consumo mundial e disponibilidade nos mercados locais.

No contexto científico, nota-se que há grande enfoque quanto à avaliação erosiva de sucos e bebidas carbonadas (LUSSI et al., 2012), porém situação diferente é observada em relação aos chás industrializados. Poucos estudos estão disponíveis na literatura avaliando 0 potencial erosivo de chás industrializados (JAÂFOURA et al., 2012), por meio da dureza superficial do esmalte.

$\mathrm{Na}$ presente pesquisa, os chás testados apresentaram baixos valores de $\mathrm{pH}$, concordando com 0 estudo Lunkes, Hashizume (2014), que também avaliaram o pH inicial e a titulação ácida de chás industrializados, comercialmente disponíveis no mercado brasileiro, e, contrários aos encontrados por Lussi et al. (2012). Todas os chás avaliados apresentaram valores de $\mathrm{pH}$ entre 2,25 e 3,39, sendo considerados bebidas cítricas, que irão promover dissolução ácida, independente da sua composição iônica relacionada ao íons cálcio, flúor e fosfato, pois seus valores de $\mathrm{pH}$ foram inferiores a 3,9 (LUSSI; GANSS, 2014).
Diante disso e analisando a composição dos mesmos, verificou-se que a maioria dos chás continha 0 ácido cítrico como acidulante, baixos valores de $\mathrm{pH}$ dos chás, do presente estudo, podem estar relacionados as suas composições, já que, os ingredientes desempenham importante papel no potencial erosivo das bebidas industrializadas (LUSSI et al., 2012; JAMEEL et al., 2016). Discordando dos resultados apresentados neste estudo, Lussi et al. (2012) encontraram pHs dos chás superiores a 5,5 , especialmente 0 chá preto, de sabor similar ao estudado corroborando Lunkes e Hashizume (2014) e Brunton e Hussain (2001). Estes achados corroboram a afirmação de que os chás, enlatados ou engarrafados, são submetidos a um processo de industrialização, no qual, são adicionados, à sua composição, diversos ingredientes, dentre eles os acidulantes (LUNKES; HASHIZUME, 2014). Logo, a adição de componentes ácidos favorece a diminuição significativa nos valores de pH das bebidas (LUSSI et al., 2012). Ademais, Jaâfoura et al. (2012) e Lunkes e Hashizume (2014) relataram maior potencial erosivo dos chás frutados, pela presença de componentes ácidos na sua fabricação, com pHs similares ao observado no presente estudo.

Dentre os chás avaliados, todos apresentaram ao menos dois tipos de ácidos nas suas composições, com exceção do chá branco (FeelGood®), 0 qual continha três tipos de ácidos e destacou-se por apresentar os maiores valores de \%PMD, superando até 0 controle positivo. Portanto, a maioria dos chás era constituído pelo ácido cítrico associado a outro ácido, tais como, 0 ácido ascórbico (vitamina C), 0 ácido fosfórico ou ácido málico. No entanto, é importante destacar que os valores reais destes ingredientes ácidos não estão disponíveis nos rótulos destes produtos e, isso já foi relatado por Rees et al. (2006). 0 ácido cítrico (encontrado no suco de laranja e no suco de limão) é um relevante componente indutor de desmineralização do esmalte dentário e encontra-se presente em diversas bebidas ácidas, que apresentam elevado potencial erosivo (REDDY et al., 2016). Este ácido dissolve os cristais de hidroxiapatita e possui capacidade quelante, ou seja, liga-se ao íon cálcio, 
o que ocasiona a remoção deste íon da superfície do esmalte, promovendo maior tendência à dissolução deste tecido dentário (LUSSI; GANSS, 2014).

A titulação ácida, nesta pesquisa, foi

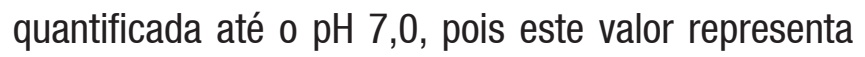
0 pH neutro para a desmineralização do esmalte. A titulação ácida determina a quantidade de ácido disponível em um determinado volume de bebida, considerando o tipo e a concentração do ácido nela presente (LUNKES; HASHIZUME, 2014). Todos os chás avaliados, neste estudo, apresentaram valores de titulação ácida e capacidade tampão abaixo do controle positivo, com exceção do chá preto com limão. No entanto, alguns estudos revelam que $0 \mathrm{pH}$ é 0 fator determinante em relação ao potencial erosivo das bebidas prontas (BARBOUR et al. 2011; LUSSI et al., 2012; BARBOUR; LUSSI, 2014), o que corrobora a presente pesquisa, na qual os chás testados, apesar de terem apresentado valores de titulação ácida e capacidade tampão abaixo do controle positivo, promoveram significativas alterações no \%PMD. Fato que pode ser explicado, provavelmente, pelos baixos valores de $\mathrm{pH}$ apresentados pelos chás testados.

A capacidade tampão, no entanto, depende da quantidade total do ácido conjugável e da base disponível, indicando a quantidade de ácido ou base que pode ser adicionada, antes do tampão perder sua habilidade de resistir à mudança de $\mathrm{pH}$ (SHELLIS et al., 2014). No meio bucal, a saliva é o fator natural mais importante (HARA; ZERO, 2014). Ela é capaz de diluir, diretamente, neutralizar e tamponar os ácidos ou impedir que os mesmos alcancem a superfície dental, assim como, tem a capacidade de remineralizar 0 esmalte pela presença de componentes inorgânicos na sua composição (BAUMANN et al., 2016). Os valores de capacidade tampão dos chás testados foram todos abaixo do controle positivo $(8,35)$, demonstrando que estas bebidas serão mais rapidamente tamponadas pela saliva, presente no meio bucal, do que a CocaCola $\circledast$.

Para 0 controle negativo, não foi realizada a titulação ácida e calculada a capacidade tampão, já que a mesma apresentou pH acima de 7,0, portanto, sugerindo a ausência de potencial erosivo, podendo ser confirmado pelos valores negativos de \%PMD apresentados. Em relação ao controle positivo (CocaCola $($ ), o mesmo apresentou maior valor de capacidade tampão, entretanto, o seu pH não foi o menor e 0 seu valor de titulação ácida foi o maior. Isso revela que a Coca-Cola $₫$, talvez, não seja a bebida com o pH mais ácido, mas, é uma bebida resistente ao tamponamento, e, que apresenta potencial erosivo, como demonstrado pelo valor do \%PMD. Este fato corrobora a afirmação de que não apenas a variável pH é capaz de predizer o potencial erosivo de uma bebida (LUSSI et al., 2012).

A dureza superficial do esmalte, aferido nesta pesquisa, é considerado um método adequado para a determinação de discretas alterações, decorrentes de ataque erosivo, na dureza de superfície (CANEPPELE et al., 2012). Todos os chás testados promoveram alteração na dureza superficial do esmalte dentário. Apenas, 0 \%PMD dos chás verde e natural do mate não demonstraram diferença estatisticamente significante em relação ao controle positivo $(p<0,05)$. Portanto, os demais chás comportaram-se como bebidas mais potencialmente erosivas que a própria Coca-Cola $₫$. Sugere-se que 0 menor \%PMD dos chás verde e natural do mate tenha sido pelo fato dos mesmos não apresentarem, em suas composições, adição de sucos de frutas. Além disso, os chás frutados apresentam altas quantidades de carboidratos e ácidos, provenientes, principalmente, do suco de limão e aromatizantes de frutas, prevalentes no seu sabor (REDDY et al., 2016), além de açúcar (JAÂFOURA et al., 2012) ou adoçante, favorecendo a um aumento do seu potencial erosivo (LUSSI; GANSS, 2014).

Analisando as correlações entre as variáveis estudadas, Hara e Zero (2008) afirmaram que exposições erosivas longas (2 horas) relacionam a erosão com a variável pH mais do que com a titulação ácida e a capacidade tampão. 0 presente estudo corrobora os resultados encontrados por Lussi et al. (2012), uma vez que foi observado que as maiores e mais fortes correlações foram vistas entre $0 \% \mathrm{PMD}$ e 0 $\mathrm{pH}$. Isto pode ser explicado pela quantidade de volume utilizado, facilitando a dissolução mineral e diminuindo 
os valores de titulação ácida e capacidade tampão (HARA; ZERO, 2008; SHELLIS et al., 2014).

Por fim, é válido ressaltar que a erosão dentária tem natureza multifatorial e se faz necessária a análise de suas variáveis em conjunto (BARBOUR; LUSSI, 2014). Logo, os achados desta pesquisa devem ser interpretados levando-se em conta as limitações da abordagem experimental adotada, uma vez que 0 estudo in vitro não reproduz todos os aspectos da dinâmica bucal, que inclui 0 processo de desmineralização e remineralização, a lavagem e neutralização proporcionada pela saliva e as outras estruturas orgânicas que estão presentes na cavidade bucal (BUZALAF et al., 2010; COMAR et al., 2013). No entanto, este tipo de estudo possibilita menor variabilidade intrínseca e melhor controle científico (BUZALAF et al., 2010) e, por isso, pode ser utilizado para aumentar a conscientização sobre a erosão dentária e elaboração de bons conselhos, direcionados à prevenção. Os cirurgiões-dentistas devem estar conscientes e convictos de quais as bebidas que podem causar erosão e de como orientar o seu consumo, para prevenir a erosão dentária (JAÂFOURA et al., 2012).

\section{CONCLUSÃo}

Diante da análise dos dados, pode-se concluir que todos os chás industrializados testados, na presente pesquisa, apresentaram caráter erosivo para 0 esmalte dentário, variando a sua intensidade conforme 0 sabor e/ou composição. A adição de sucos de frutas aos chás provocou aumento no seu potencial erosivo, relacionado com a titulação, 0 pH e 0 \%PMD. As variáveis químicas analisadas e a perda de dureza estão correlacionadas entre si, podendo explicar 0 potencial erosivo das bebidas estudadas.

\section{REFERÊNCIAS}

ALVAREZ, L. L.; FABRUCCINI, F. A.; ALVES, L.S.; ALVAREZ , V. R.; MALTZ, M. Erosive Tooth Wear among 12-YearOld Schoolchildren: A Population-Based CrossSectional Study in Montevideo, Uruguay. Caries Res., v. 49, n. 3, p. 216-225, 2015.

BARBOUR, M. E.; LUSSI, A.; SHELLIS, R. P. Screening and Prediction of Erosive Potential.Caries Res, v. 45, p. 24-32, 2011.

BARBOUR, M. E.; LUSSI, A. Erosion in relation to nutrition and the environment. Monogr Oral Sci., v. 25, p. 14354, 2014.

BAUMANN, T.; KOZIK, J.; LUSSI, A.; CARVALHO, T. S. Erosion protection conferred bywhole human saliva, dialyzed saliva, and artificial saliva. Sci Rep., v. 5, n. 6, p. 34760 , oct 2016.

BRUNTON, P. A.; HUSSAIN, A. The Erosive Effect of Herbal Tea on Dental Enamel. Journal of Dentistry, $v$. 29, n. 8, p. 517-520, 2001.

BUZALAF, M. A. R; HANNAS, A. R.; MAGALHÃES, A. C.; RIOS, D.; HONÓRIO, H. N.; DELBEM, A. C. B. pHcycling models for in vitro evaluation of the efficacy of fluoridated dentifrices for caries control: strengths and limitations. J. Appl. Oral. Sci., v. 18, n. 4, p. 316-334, 2010.

CANEPPELE, T. M.; JERONYMO, R. D.; DINICOLÓ, R; ARAÚJO, M. A.; SOARES, L. E. In Vitro assessment of dentin erosion after immersion in acidic beverages: surface profile analysis and energy-dispersive $X$-ray fluorescence spectrometry study. Braz Dent J, v. 23, p. 373-378, 2012.

CARVALHO, T.S.; LUSSI, A.; JAEGGI, T.; GAMBON, D.L. Erosive tooth wear in children. Monogr Oral Sci, v. 2, p. 262-78, 2014.

COMAR, L. P.; SOUZA, B. M.; GRACINDO, L. F.; BUZALAF, M. A. R.; MAGALHÃES, A. C. Impact of experimental 
nano-hap pastes on bovine enamel and dentin submitted to a ph cycling model. Braz. Dent. J., v. 24, n. 3, 2013.

GONÇALVES, G. K. M.; GUGLIELMI, C. A. B.; CORRÊA, F. N. P.; RAGGI0, D. P.; CÔRREA, M. S. N. P. Erosive potential of different types of grape juices. Braz Oral Res., São Paulo, v. 26, n. 5, p. 457-463, set./out. 2012.

HARA, A. T.; ZER0, D. T. Analysis of the erosive potential of calcium-containing acidic beverages. Eur $\mathbf{J}$ Oral Sci, v. 116, p. 60-65, 2008.

HARA, A. T.; ZERO, D. T. The potential of saliva in protecting against dental erosion. Monographs in oral science, v. 25, p.197-205, 2014.

JAÂFOURA, S.; KHEMISS, F.; KAMMOUN, D.; CHEBBI, R.; BACCOUCHE, C.; GHOUL-MAZGAR, S. Dental Erosion and Tea: A Systematic Review. IJSR. v. 3, n. 11, p. 2436-2439, 2012.

JAEGGI, T.; LUSSI, A. Prevalence, Incidence and Distribution of Erosion. Monogr Oral Sci., v. 25, p. 5573, 2014.

KREULEN, C.; VAN 'TSPIJKER, A.; RODRIGUEZ, J.; BRONKHORST, E.; CREUGERS, N. et al. Systematic review of the prevalence of tooth wear in children and adolescents. Caries Res, v. 44, p. 151-159, 2010.

LUNKES, B. F.; LINA, N. H. Evaluation of the pH and Titratable Acidity of Teas Commercially Available in Brazilian Market. Rev Gaúcha Odontol, v. 62, n. 1, p. 59-64, 2014.

LUSSI, A.; KOHLER, N.; ZERO, D.; SCHAFFNER, M.; MEGERT, B. A comparison of the erosive potential of different beverages in primary and permanent teeth using an in vitro model. Eur J Oral Sci., v. 108, n. 2, p. 110-114, abr. 2000.

LUSSI, A.; SCHLUETER, N.; RAKHMATULLINA, E.; GANSS, C. Dental erosion: an overview with emphasis on chemical and histopathological aspects. Caries
Res., v. 45, n. 1, p. 2-12, 2011.

LUSSI, A.; MEGER, B.; SHELLIS, R. P.; WANG, X. Analysis of the erosive effect of different dietary substances and medications. Brit J Nutr., v. 107, p. 252-262, 2012.

LUSSI, A.; GANSS, C. Erosive tooth wear. Monogr Oral Sci.,v. 205, p. 1-15, 2014.

MESSIAS, D. C. F.; SERRA, M. C.; TURSSI, C. P. Estratégias para prevenção e controle da erosão dental. Rev Gaúcha Odontol., Porto Alegre, v. 59, suplemento 0, p. 7-13, jan./jun., 2011.

MULLER-BOLLA, M.; COURSON, F.; SMAIL-FAUGERON, V.; BERNARDIN, T.; LUPI-PÉGURIER, L. Dental erosion in French adolescents. BMC Oral Health., v. 15, p. 147, 2015.

REDDY, A.; NORRIS, D. F.; MOMENI, S. S.; WALDO, B.; RUBY, J. D. The pH of beverages in the United States. J Am Dent Assoc. v. 147, n. 4, p. 255-263, 2016.

REES, J. S.; LOYN, T.; ROWE, W.; KUNST, Q.; MCANDREW, $R$. The ability of fruit teas to remove the smear layer: an in vitro study of tubule patency. J. Dent., v. 34, p. 67-76, 2006.

SHELLIS, R. P.; ADDY, M. Interaction between attrition, abrasion and erosion in tooth wear. Erosive Tooth Wear. Monog Oral Sci, v. 25, p. 32-45, 2014.

SHELLIS, R. P.; FEATHERSTONE, J. D.; LUSSI, A. Understanding the chemistry of dental erosion. Monog Oral Sci, v. 25, p. 163-179, 2014.

SINGH, S.; JINDAL, R. Evaluating the buffering capacity of various soft drinks, fruit juices and tea. $\mathbf{J}$ Conserv Dent. v. 13, n. 3, jul, p.129-130, 2010.

WEST, N. X.; JOINER, A. Enamel mineral loss. J Dent. v. 42, suppl 1, jun, p. 2-11, 2014.

Recebido em: 31 de Agosto de 2017 Aceito em: 19 de outubro de 2017 